Perspective

\title{
In silico testing of the ability of meniscus implant to convert compressive loads in to hoop stresses
}

\author{
Volume 4 Issue 4 - 2016 \\ Khalifa Elmajri \\ Claude Bernard University Lyon, France
}

\author{
Correspondence: Khalifa Elmajri, MD Msc Biomech, Fellow \\ Center Albert Trillat, Lyon France, Tel 33600000000 , \\ Email kelmajri@gmail.com
}

Received: January 01, 2016 | Published: February 18, 2016 avascular nature and the treatment using lazy dull ectomy ${ }^{1}$ is no longer a choice. This part, unfortunately, is the most injured part of the meniscus. This exceptional paradox needs exceptional interdisciplinary approach based on new concepts, Biological Surgery. ${ }^{2}$

In 2009, Rick W. Wright wrote, the majority of meniscus tears observed at the time of ACL reconstruction are still treated by partial meniscectomy $(55 \%$ medial meniscectomy, $67 \%$ lateral meniscectomy). A relatively large potential market (approximately $160,000)$ exists for functional tissue engineering strategies to preserve meniscus function through scaffolds (approximately 74,000), advancing repairs to avascular zone (approximately 56,000) and performing all-biologic repairs without implants (approximately $30,000)$. We hope that many of these options will be available in the future. End citation

Though it is clear that the investment in the treatment of this issue is an excellent business affaire; however, the inexperienced out of the field-essence approaches lead to inverted cost-effectiveness. ${ }^{3}$ With the help of the Advances in the IT, Different planning of Treatment Can Be credited When Compared to the in silico Simulation of the implant. ${ }^{4}$ From this point of view, a Project concerning meniscal replacement options can be raised.

\section{Polyvinyl alcohol (PVA) hydrogel}

The polyvinyl alcohol (PVA) hydrogel ${ }^{5,6}$ implant of Kobayashi et $\mathrm{al}^{7}$ was one of the first non-porous permanent replacement approaches. Compressive strength and viscoelastic behavior of the material was highly similar to that of the native (human) meniscus, even after two years of implantation in a rabbit knee. The implant proved to be chondro protective when compared to meniscectomy; however, no sham-operated controls were included to evaluate the influence of the replacement surgery on cartilage condition. ${ }^{8}$ In a large animal model, however, the implant caused severe damage to the articular cartilage and benefits in comparison with meniscal allograft could not be proven. Moreover, structural integrity was compromised by complete radial tears in the posterior horn of all implants. It was speculated that the adverse effects were caused by hypermobility of the implant's body. ${ }^{9}$

Recently, an American group has renewed interest in PVA hydrogels for meniscal substitution. It has been shown that by the incorporation of polyethylene fibres into the hydrogel both the compressive and tensile moduli of the biomaterial can be tuned to resemble that of the native meniscus, ${ }^{10}$ which is an important step towards the ability of any meniscus implant to convert compressive loads into hoop ${ }^{11}$ stresses. In Simulating the polyvinyl alcohol (PVA) hydrogel would be conceived as Knee Interposition Distraction Meniscus.

\section{Some roadmaps to approach the idea :}

I. Using Medical 3D Imaging Extracted from MRI.

II. 3D Printing of the (PVA) as different Knee Interposition Distraction Meniscus.

III. In Silico Testing by simulation.

\section{Benefits}

i. The conception of (PVA) as KIDM Can Be controlled in a manner that The Alteration of the Knee Compartments Biomechanics caused by Meniscus replacement can be monitored In Silico.

ii. Improvement of credibility-cost-effectiveness $\operatorname{triad}^{12}$ for translational Animal ${ }^{13}$ Research in Sports Medicine. ${ }^{14,15}$

\section{In silico testing of (PVA) as (KIDM) can be}

a. A Simulation of Total, Partial, Temporary, Permanent replacement.

b. A Simulation of Traumatology. ${ }^{16}$

c. A Simulation of Mechanical Knee Deviations in Multiple Planes. $^{17}$

d. A simulation of Meniscus repair. ${ }^{18,19}$

e. A Simulation of Meniscus Surfacing. ${ }^{20}$

f. Simulation Cartilage Surfacing or Replacements ${ }^{21}$ by the interface of (PVA).

When all the hope is expected from one scientific branch, as nowadays in the case of genetic engineering, then the security cannot be totally secured ${ }^{22}$ simply because the wholeburden is put on one side.

\section{Acknowledgments}

None. 


\section{Conflicts of interest}

None.

\section{References}

1. Neuman P, Läkare L, Anterior Cruciate Ligament Injury, Patient Variables, Outcomes And Knee Osteoarthritis. 2010;pp:1-135.

2. https://www.linkedin.com/pulse/dull-ectomy-longer-choice-khalifaelmajri

3. Seil R. Thirty years of arthroscopic meniscal suture: What's left to be done? Orthopaedics \& Traumatology: Surgery \& Research 2009;95(8):85-96.

4. Pal US, Singh N, Malkunje LR, et Al. Retrospective Study Of Absorbable Gelatin Sponge Soaked In Triamicinolone Acetonide As Interpositioning Material In Temporomandibular Joint Ankylosis In 350 Patients. J Oral Biol Craniofac Res. 2009;3(1):20-24.

5. Longo UG, Campi S, Romeo $\mathrm{G}$, et al. Biological strategies to enhance healing of the avascular area of the meniscus. Stem Cells Int 2012:528359.

6. Rizky NHP, Heka P, Andri MTL. Effect of distraction arthroplasty on osteoarthritic goat models of the articular cartilage. Med $J$ indons. 2013;22(2):64-69.

7. Maritz L. A retrospective review of a series of interposition arthroplasties of the elbow. SAGE Journals. 2014;6(2):129-133.

8. Kobayashi M, Toguchida J, Oka M. Preliminary study of polyviny alcohol-hydrogel (PVA-H) artificial meniscus. Biomaterials. 2003;24(4):639-647.

9. Kobayashi M, Chang YS, Oka M. A two year in vivo study of polyvinyl alcohol-hydrogel (PVA-H) artificial meniscus. Biomaterials. 2005;26(16):3243-3248.

10. Kelly BT, Robertson W, Potter HG, et al. Hydrogel meniscal replacement in the sheep knee: preliminary evaluation of chondro protective effects. Am J Sports Med. 2007;35(1):43-52.
11. Holloway JL, Lowman AM, Palmese GR. Mechanical evalu ation of poly (vinyl alcohol)-based fibrous composites as biomaterials or meniscal tissue replacement. Acta Biomater. 2010;6(12):4716-4724.

12. Chevrier A, Nelea M, Hurtig MB, et al. Meniscus structure in human, sheep, and rabbit for animal models of meniscus repair. J Orthop Res. 2009;27(9):1197-1203.

13. Why Are Animals Necessary in Biomedical Research? California Biomedical Research Association.

14. Krueger CA, Wenke JC, Masini BD, et al. Characteristics and impact of animal models used for sports medicine research. Orthopedics. 2012;35(9):1410-1415.

15. Sah RL, Ratcliffe A. Translational models for musculoskeletal tissue engineering and regenerative medicine. Tissue Eng Part B Rev. 2010;16(1):1-3.

16. Johnson D. Arthroscopic Meniscus Repair. 2000;p.1-14.

17. McNulty AL, Guilak F. Integrative repair of the meniscus: lessons from in vitro studies. Biorheology. 2009;45(3-4):487-500.

18. Scotti C, Hirschmann MT, Antinolfi P, et al. Meniscus repair and regeneration: review on current methods and research potential. Eur Cell Mater. 2013;26:150-170.

19. Barber FA, Herbert MA, Richards DP. Load to failure testing of new meniscal repair devices. Arthroscopy. 2004;20(1):45-50.

20. Stärke C, Kopf S, Petersen W, Becker R. Meniscal repair. Arthroscopy. 2009;25(9):1033-1044.

21. Bueche MJ, Phillips WA, Gordon J, et al. Effect of interposition material on mechanical behavior in partial physeal resection: a canine model. $J$ Pediatr Orthop. 1990;10(4):459-462.

22. Findinier Isabelle. Biotechnologies Appliquees Aux Animaux : Etat Des Lieux, Risques Et Perspectives, FAO. 2003;p:1-43. 